\title{
The Development of Virtual Museum for Thai Style Houses in Four Regions
}

\author{
P. Jomsri
}

\begin{abstract}
These currently, the educated sources for Thai local cultures and Thai folk wisdoms still do not exist in online multimedia. In order to spread Thai folk wisdoms on Thai style house building similar to the real thing, a researcher gathered and presented in form of Virtual Museum which imitate the real places, as well as developed to integrate with the website so that any people who are interested in can study through this Virtual Museum. In addition, people can view the differences of Thai style houses in four regions which this was difficult to do previously.

From the experiment by the users, it showed that they increased knowledge about Thai style houses in four regions, as well as they were satisfied in the system mostly. In sum up, Virtual Museum of Thai style houses in four regions can support in educating people about Thai cultures efficiently.
\end{abstract}

Index Terms - Virtual museum, Thai style houses.

\section{INTRODUCTION}

When considering in Thai cultures and Thai local wisdoms related to houses in each regions, people, who are not in organizations or institutes that involve in this field, have known very few, or rarely have a chance to study about Thai cultures and Thai local wisdoms because to learn about Thai houses, it needs to visit the sites themselves which is the field study in order to help learners receive real experience, and view the real place. However, a field study is very costly, and takes time, as well as it is very difficult. Moreover, the current sources are not similar to Thai houses in the past since there are only pictures or textbooks only. In information technology era, only primitive kinds of media seem lack to draw attention from people.

Thai houses and local wisdom in housing among Thai people in four regions were an example that a researcher found that it is very important in cultures and values to help new generation learn and interest about the local architectures in four regions. Each region has different styles, architectures, and local wisdoms. Currently, modern technology, that has been developing both in systems and programs, including internet, website, and ect., influences in solving that difficulty. Yaowalak Tianbanjong and friends (2544:9-13) said that society in the present fills with many kinds of media so that sufficient educational materials is very important because they can help in learning, teaching, and researching information. Integrating with good designed programs will benefit to teaching and further researching. Likewise, Virtual Museum is a kind of technology innovation

Manuscript received October 11, 2014; revised December 12, 2014.

P. Jomsri is with the Faculty of science and technology, Suan Sunandha Rajabhat University, Dusit, Bangkok 10300 Thailand (tel.: +6602-160-1143; e-mail: pijitra.jo@ssru.ac.th, pijitra_jom@hotmail.com). which supports in learning and fulfilling viewers either students or people. Stories or activities from Virtual Museum can be learned practically through many kinds of technology.

From the difficulty in presenting Thai cultures and Thai local wisdoms in Thai style houses in four regions, as well as the advanced development in technology, a researcher would like to study the efficiency in using Virtual Museum to present the data of Thai style houses in four regions by creating from computer program. The hypothesis of a researcher is that by presenting Thai style houses in for region through Virtual Museum, it will increase the knowledge among Thai people, as well as make them interest in Thai houses increasingly.

This research is included: Section II discusses related works. The framework of this paper is described in Section III. The development system and evaluation system explained in Section IV. The Results and discussions from the experiments are presented in Section V. Finally, the conclusion and future work are given in Section VI.

\section{RELATED WORK}

Virtual Museum is a kind of exhibition which is designed to draw attention from viewers. By using modern technology, communication and internet, it creates multimedia and mixed media in 3D both still pictures and motion pictures that can view and listen. Otherwise, viewers can view a short clip, and feel as they are in the real site. These save time, energy, and budget from traveling to the real sites, as well as they can move the objects around to view it closely. Many researchers develop virtual system for public cultures, travels and studies. Jomsri [1] presented Virtual Temple. The prototype, which is a replica of the actual location, was developed to the website and allows people who are interested in Rattanakosin Island can see in form of Panorama Pan View. Khainaga [2] built a museum presentation about Thai architecture: case study Thai Lue houses, and studied the effectiveness of learning in virtual presentation. The study found that following the virtual media museum of Thai Lue houses, the understanding of students.

VolkanIsler and et al. [3] have created a system for the analysis and display of a collection of Native Californian baskets of Phoebe A. Hearst Museum of Anthropology. This research differs from existing cultural heritage applications in terms of the focus on tools and techniques to display objects, and to study the related ones. In the case of the basket, researchers developed a model in 3D, and exhibits in virtual view.

Chai Yu Tai [4] has created a guide for temples in Taipei for tourists. This research focuses on using Macromedia Flash program as a tool in creating parts of the tour in order to 
be used in Pocket PC. The user can interact with the map by the interactive panoramic images showing places where they want to see or where to go on the map immediately. Tourists can travel more easily and faster through information and images that appear in the panoramic virtual on Pocket PC.

LI Fung-Chun and et al. [5] studied the effect of using a virtual environment that affect the learning of students in National Tainan Teachers College, Department of Earth Science by dividing into two groups: the experimental group learned to create websites with VRML language and the first control group learned from the virtual environment of the mountain city images in 3D. The second control group of students learned from normal method then measured their understanding of the difference of the scores on the test before and after learning (Pre-test \& Post-test). The results concluded that the use of virtual reality making the students better understand than the students who studied through normal pictures. Thus, the freely control system will help them better in learning and in exploring the environment.

Pavlicek [6] was able to place the model in computer science using virtual panorama for PanoramicModel of the Department of Computer Science, FEE CTU. The purpose of the research was to create a model place of computer science using Quick Time VR: QTVR, where the audiences are feeling as they are in the real place, and can really set the direction to walk in, and view information about the property as well. Yodsin [7] studied the effect of using panoramic virtual slides in the study on the web for the academic achievement of students at Mattayom 4. The study found that students learned from field trips on the Web by using panoramic virtual could achieve better than students who studied with educational field trips on the Web by using a slide.

Poompaga [8] studied the education content and site layout of Thai museum websites. The samples are registered and unregistered websites with the names of "museums" in the sites, and there is a direct link to the page with the content of the museums for 28 sites in Thailand. The study found that, in terms of content, the content is mainly the history of the museum, and objects in museum, exhibition, and activities. The advertising section in the website did not focus on using multimedia both Thailand and English language together with links to other sites. In addition, they did not install chat rooms and online activities to entertain the audience. Hagward [9] said the three-dimensional and three-dimensional animation has been applied widely in the study of science or learning of the true or real environment may require substantial costs. Hence, three dimensions will become really important in the education. Some researcher use local wisdom innovation in cultural heritage [10].

This paper uses different views to develop virtual museum of Thai style for public wisdom.

\section{FRAMEWORK OF VIRTUAL MUSEUM FOR THAi STYLE HOUSES IN FOUR REGIONS}

In developing Virtual Museum for Thai style houses in four regions, this is to spread Thai local wisdoms to Thai people and foreigners, as well as the information can serve in planning traveling. There are 7 steps in developing as following:

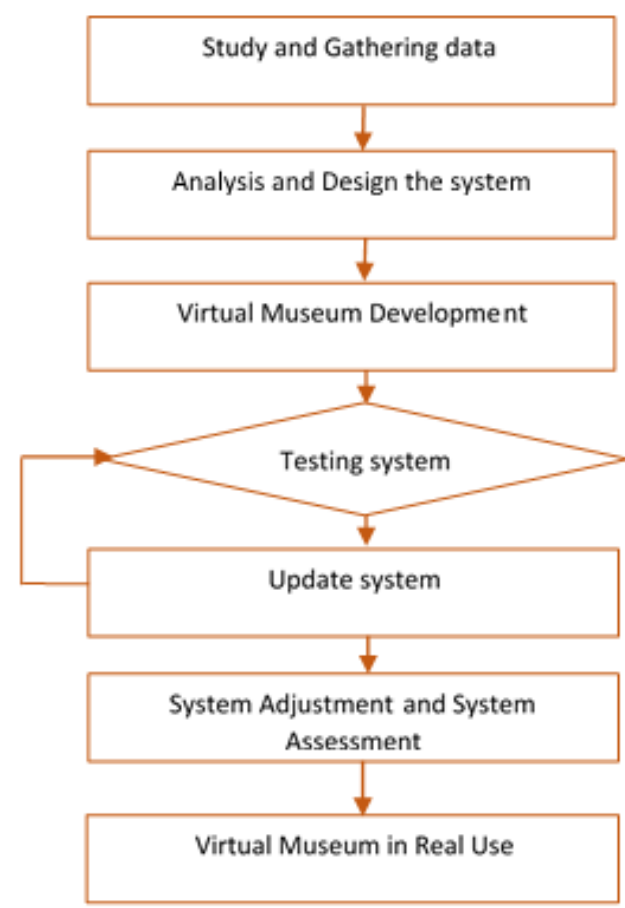

Fig. 1. A framework for preliminary development of virtual museum.

\section{A. Study and Gathering Data}

A researcher studied and gathered data, differences, and took photo from the real sites both in text, visual, and audio covering Thai styles houses in four regions.

\section{B. Analysis and Design the System}

Through analyze systems and web design, the web structure is designed according to the information technology to present the details in Thai style houses in four regions such as pillars, gables, and construction regarding regions and living styles.

\section{Virtual Museum Development}

A researcher develops virtual museum regarding analysis and system designs.

\section{Testing}

Virtual museum is tested regarding analysis and systems designs by the experts.

\section{E. System Adjustment}

System Adjustment is gathering feedbacks from users, and assesses the data. Later, this brought to adjust and develop the website in order to maximize the efficiency, and minimize the errors.

\section{F. System Assessment}

To assess virtual museum, the samples of users were selected through questionnaires. Then, the data brought to analyze the hypothesis.

\section{G. Virtual Museum in Real Use}

This process is to bring the system into the real use through network.

\section{DEVElopment And Evaluation SyStem}

There are 2 parts: System development and System assessment. 


\section{A. System Development}

To develop the system, a researcher used Visual C\#, Adobe, and took pictures and important parts of Thai style houses in four regions. Fig. 2-Fig. 5 show an example of development process.

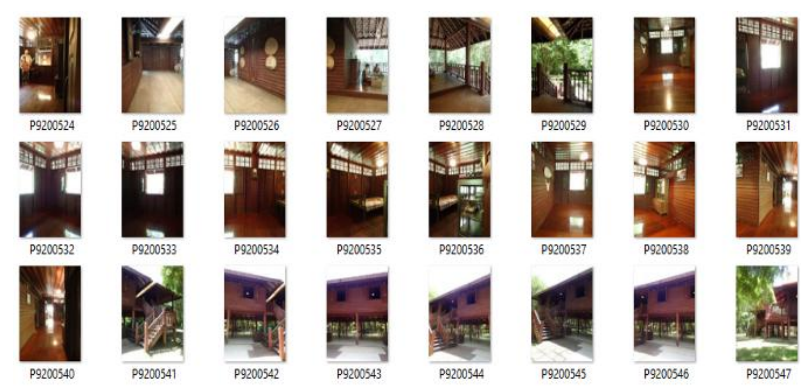

Fig. 2. Example of Thai style houses.

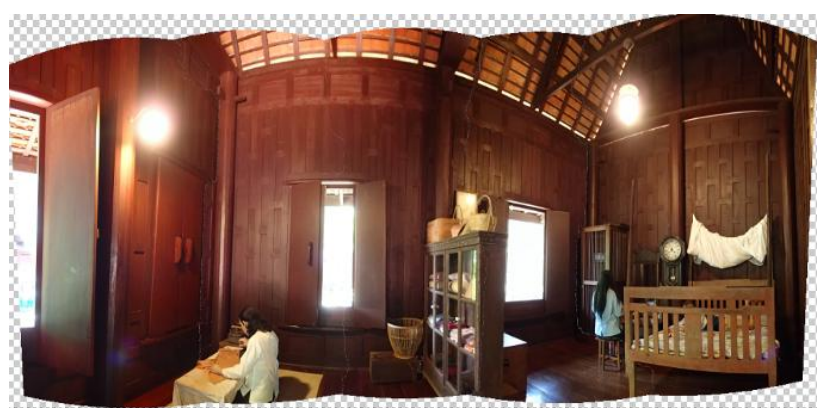

Fig. 3. Process of merging temple image.

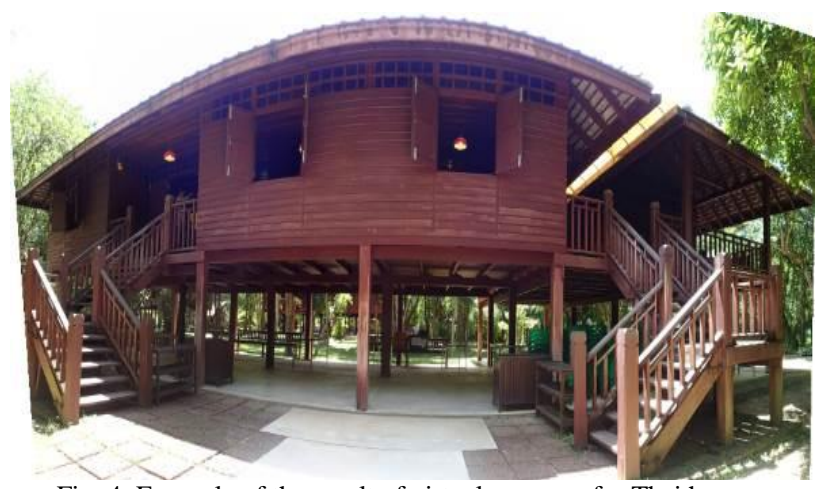

Fig. 4. Example of the result of virtual museum for Thai house.

\section{B. System Assessment}

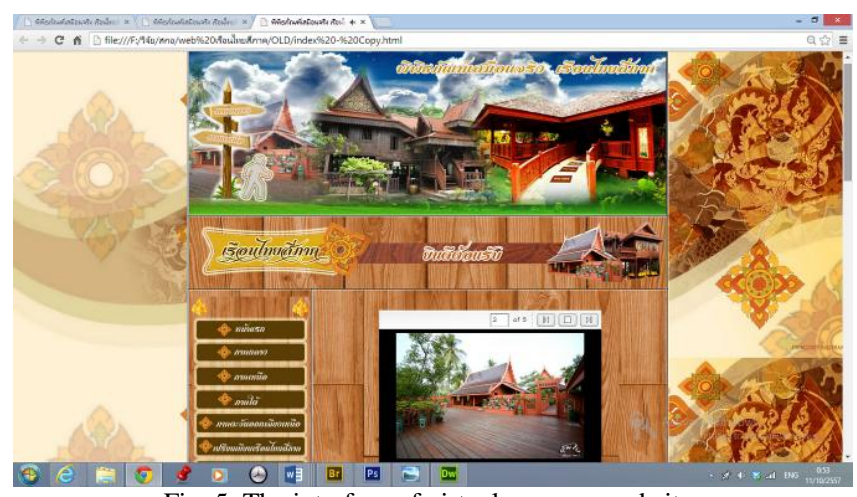

Fig. 5. The interface of virtual museum website.

To assess the systems, a researcher asked 50 system experts including students and other people to volunteer in assessment. The subjects were asked to rate the relevancy of the search results on a five-point scale: Score 1 is the level of satisfaction improvement, Score 2 is minimum level of satisfaction, Score 3 is medium level of satisfaction, Score 4 is good and Score 5 is very good satisfaction. Moreover, a researcher used $T$-test in analyzing the data before and after using the systems.

\section{RESUlT AND DISCUSSION}

The result of assessment from 50 subjects in satisfaction in Virtual Museum of Thai style houses in four regions showed that system reliability and information was 4.40 and reliability was 0.648 which was in good level as shown in following Table I-Table II:

TABLE I: THE RESULT OF THE ASSESSMENT

\begin{tabular}{|c|c|c|c|c|}
\hline No & Assessment Items & $\begin{array}{l}\text { Overall } \\
\text { Average }\end{array}$ & Reliability & Criteria \\
\hline 1 & $\begin{array}{l}\text { Learn more about Thai } \\
\text { style houses in } 4 \\
\text { regions }\end{array}$ & 4.65 & 0.205 & Very good \\
\hline 2 & Design and Structure & 3.91 & 0.111 & Good \\
\hline 3 & Fonts & 4.15 & 0.206 & Good \\
\hline 4 & Colors & 3.87 & 0.126 & Good \\
\hline 5 & $\begin{array}{l}\text { Pictures and } \\
\text { multimedia }\end{array}$ & 4.09 & 0.259 & Good \\
\hline 6 & $\begin{array}{l}\text { Designs are suitable to } \\
\text { users }\end{array}$ & 4.44 & 0.578 & Good \\
\hline & Total & 4.40 & 0.648 & Good \\
\hline
\end{tabular}

To test the mean difference by use assumption that the knowledge of user about Thai house style between before (BHModel) and after (AHModel) use virtual museum system are difference, a paired-sample $\mathrm{T}$ test is employed. Assume that the sample comes from populations that are approximately normal with equal variances. Level of significance is set to $0.05(\alpha=0.05)$. The results can be summarized as follows:

\begin{tabular}{ccccc}
\multicolumn{4}{c}{ TABLE II: PAIRED-SAMPLE T TEST } \\
\hline \hline \multirow{3}{*}{ Pair } & Mean & $\begin{array}{c}\text { Pair differences } \\
\text { Deviat } \\
\text { ion }\end{array}$ & $\begin{array}{c}\text { Std.error } \\
\text { Mean }\end{array}$ & Sig \\
& & .057 & .274 & .001 \\
\hline BHModel - AHModel & .091 & .057 & \\
\hline \hline
\end{tabular}

The statistical testing result from Table II indicates that there is a significant difference in the confidence values of the BHModel and AHModel at $\alpha=0.05$. In other words, the mean scores of confidence values of BHModel and AHModel are not the same. Therefore virtual museum for Thai style houses in four regions can help to public Thai wisdom.

\section{CONCLUSION AND FUTURE WORK}

This research developed Virtual Museum of Thai style houses in 4 region by studying the data from many sources such as Thai style houses information and the real museum that exhibit Thai style house, as well as visiting the real sites in order to develop the systems.

The result from the development of Thai style houses in 4 regions brought to help the developer to learn what the users really need, and make it easy to use in all ages. The system works continuously and efficiently in the real use.

Further study can be done to add in more Thai style houses in 4 regions, and create social network or exchange the ideas among the users. Likewise, creating a website to support 
AEC or in other languages to make Thai cultures be known widely.

\section{ACKNOWLEDGMENT}

The authors would like to thank Suan Sunandha Rajabhat University for scholarship support.

\section{REFERENCES}

[1] P. Jomsri, "A preliminary development of virtual sightseeing website for thai temples on rattanakosin island," International Journal of Social, Management, Economics and Business Engineering, vol. 7, no. $12,2013$.

[2] G. Khainaga, "The creation of virtual museum for promoting education in thai architecture: A case study of Thai lue house," Master Thesis, Chiangmai University, 2008.

[3] V. Isler, B. Wilson, and R. Bajcsy. Building a 3D virtual museum of native american baskets. [Online]. Available: http://www-users.cs.umn.edu/ isler/pub/3dpvt06.pdf

[4] Chai-Yu-Tai, Temple of Taipai a handheld Tour Guide for Pocket PC, Department of Telecommunication, Michigan state University, 2003.

[5] L. Fung-Chun, J. Angelier, B. Deffontaines, H. Jyr-Ching, H. Shih-Hao, C. Lee, C. Huang, and C. Chen, "A virtual reality application for distance learning of taiwan stream erosion in geoscience," in Proc. ICCE 2002, 2002, pp. 1156-1160.
[6] D. Pavlicek. Panoramic model of the department of computer science. FEE CTU. [Online]. Available: http://www.cgg.cvut.cz/publication/diplom/PavlicekDusan/abstract_ht $\mathrm{m}$.

[7] N. Yodsin, "Effects of virtual panorama image in educational field trips on web upon learning achievement of mathayom suksa four students," Thesis, Chulalongkorn University, 2004.

[8] W. Poompaga, "Educational content and layout of the site in Thailand Museum," Master Thesis, Mahidol University, 2001.

[9] T. Hagward, "Adventure in virtual reality," Indianapolis: Que Corporation, 1993, p.110.

[10] J. Boonpracha, "Local wisdom innovation in cultural heritage of applying relation between colors of five element and colors of benjarong to develop souvenir product of communities," Office of the Higher Education Commission, 2011.

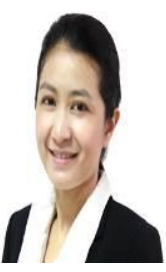

P. Jomsri was born in Thailand in 1981. She received her B.Sc in statistic degree from Thamasat University, and M.S. in computer science from Slipakorn University. She received her doctorate degree from Chulalongkorn University in 2013 in the field of computer science and information technology. She working as an assistant director of academic resource center and is a lecturer in major information technology at Suan Sunandha Rajabhat University. Her research work is in the areas of virtual system, information retrieval, web technology and network system. 